\title{
Outcomes of Pediatric Patients with Therapy-Related Myeloid Neoplasms
}

Akshay Sharma, MBBS,${ }^{*}$ Sujuan Huang, MSPH,${ }^{2}$ Ying Li, MD, ${ }^{1}$ Russell J. Brooke, $\mathrm{PhD},{ }^{2} \mathrm{Ibrahim}$ Ahmed, MD, ${ }^{3}$ Heather B. Allewelt, MD, MHS, ${ }^{4}$ Persis Amrolia, MBBS, FRCP, 5 Alice Bertaina, MD, PhD, ${ }^{6}$ Neel S. Bhatt, MBBS, MPH, ${ }^{7}$ Marc B. Bierings, MD, $\mathrm{PhD},{ }^{8}$ Joshua Bies, MD, ${ }^{9}$ Claire Brisset, MD, MSc, ${ }^{10}$ Jennifer E. Brondon, MD, ${ }^{11}$ Ann Dahlberg, MD, ${ }^{7}$ Jean-Hugues Dalle, MD, PhD, ${ }^{10}$ Hesham Eissa, MD, MSc, ${ }^{12}$ Mony Fahd, MD, MSc, ${ }^{10}$ Adam Gassas, MBChB, MSc, FRCP, DCH, ${ }^{13}$ Nicholas J. Gloude, MD, ${ }^{14}$ W Scott Goebel, MD, PhD, ${ }^{15}$ Erika S. Goeckerman, MSN, CPNP, ${ }^{11}$ Katherine Harris, MD, ${ }^{16}$ Richard Ho, MD, ${ }^{17}$ Michelle P. Hudspeth, MD, ${ }^{18}$ Jeffrey S. Huo, MD, $\mathrm{PhD},{ }^{19}$ David Jacobsohn, MD, ${ }^{16}$ Kimberly A. Kasow, DO, ${ }^{9}$ Emmanuel Katsanis, MD, ${ }^{20}$ Saara Kaviany, DO, ${ }^{17}$ Amy K. Keating, MD, ${ }^{21}$ Nancy A. Kernan, MD, ${ }^{22}$ Yiouli P. Ktena, MD, ${ }^{23}$ Colette R. Lauhan, MD, ${ }^{14}$ Gerardo López-Hernandez, MD, ${ }^{24}$ Paul L. Martin, MD, PhD, ${ }^{11}$ Kasiani C. Myers, MD, ${ }^{25},{ }^{26}$ Swati Naik, MD, ${ }^{27}$ Alberto Olaya-Vargas, MD, ${ }^{24}$ Toshihiro Onishi, MD, ${ }^{27}$ Mohamed Radhi, MD, ${ }^{3}$ Shanti Ramachandran, MBBS, FRACP, ${ }^{28}$ Kristie Ramos, MD, ${ }^{20}$ Hemalatha G. Rangarajan, MD, ${ }^{29}$ Philip A. Roehrs, MD, ${ }^{19}$ Megan E. Sampson, MD, ${ }^{25,}{ }^{26}$ Peter J. Shaw, MD, ${ }^{30}$ Jodi L. Skiles, MD, MS, ${ }^{15}$ Katherine Somers, MD, ${ }^{28}$ Heather J. Symons, MD, MHS, ${ }^{23}$ Marie de Tersant, MD, MSc, ${ }^{10}$ Allison N. Uber, MD, ${ }^{18}$ Birgitta Versluys, MD, PhD, ${ }^{8}$ Cheng Cheng, PhD, ${ }^{2}$ Brandon M. Triplett, MD ${ }^{1}$.

1 Bone Marrow Transplantation and Cellular Therapy, St. Jude Children's Research Hospital, Memphis, TN, USA

2 Biostatistics, St. Jude Children's Research Hospital, Memphis, TN, USA

3 Pediatric Hematology, Oncology and BMT, Children's Mercy Hospital Kansas City, Kansas City, MO, USA

4 Pediatric Hematology Oncology, AdventHealth for Children, Orlando, FL, USA

5 Department of Bone Marrow Transplant, Great Ormond St Children's Hospital, London, UK

6 Stem Cell Transplantation and Regenerative Medicine, Department of Pediatrics, Stanford School of Medicine, Stanford, CA, USA

7 Clinical Research Division, Fred Hutchinson Cancer Research Center, Seattle, WA, USA

8 Stem cell transplantation, Princess Maxima Centre for Pediatric Oncology, Utrecht, Netherlands

9 Pediatrics, University of North Carolina, Chapel Hill, NC, USA

10 Hemato-immunology Department, Robert Debré Hospital, GHU APHP Nord -

Université de Paris, Paris, France

11 Pediatric Transplant and Cellular Therapy, Duke University School of Medicine, Durham, NC, USA

12 Blood and Marrow Transplant and Cellular Therapeutics, Center for Cancer and Blood Disorders, Children's Hospital Colorado, Aurora, CO, USA

13 Department of Haematology and Oncology, Royal Hospital for Children, Bristol, UK 14 Pediatrics, University of California San Diego, Rady Children's Hospital San Diego, San Diego, CA, USA 
15 Pediatrics, Riley Hospital for Children at IU Health, Indiana University School of Medicine, Indianapolis, IN, USA

16 Blood and Marrow Transplantation, Children's National Hospital, Washington, DC, USA

17 Pediatric Hematology, Oncology and BMT, Vanderbilt University Medical Center, Nashville, TN, USA

18 Pediatric Hematology and Oncology, Medical University of South Carolina, Charleston, SC, USA

19 Pediatric Cellular Therapies, Cancer and Blood Disorders, Atrium Health Levine Children's hospital, Charlotte, NC, USA

20 Pediatrics, University of Arizona, Tucson, AZ, USA

21 Department of Pediatrics, University of Colorado School of Medicine, Aurora, CO, USA

22 Pediatrics, Memorial Sloan Kettering Cancer Center, New York City, NY, USA

23 Pediatric Oncology, Sidney Kimmel Cancer Center, Johns Hopkins University, Baltimore, MD, USA

24 Bone Marrow Transplant and Cell therapy Department, National Institute of

Pediatrics, Ciudad de Mexico, Coyoacan, Mexico

25 Department of Pediatrics, University of Cincinnati College of Medicine, Cincinnati, $\mathrm{OH}, \mathrm{USA}$

26 Division of Bone Marrow Transplantation and Immune Deficiency, Cincinnati Children's Hospital Medical Center, Cincinnati, OH, USA

27 Center for Cell and Gene Therapy, Texas Children's Hospital, Baylor College of Medicine, Houston, TX, USA

28 Oncology, Haematology, Blood and Marrow Transplantation, Child and Adolescent Health Services, Perth Children's Hospital, Nedlands, Western Australia, Australia 29 Hematology, Oncology, Blood and Marrow Transplant, Nationwide Children's Hospital, Columbus, OH, USA

30 Children's Hospital at Westmead, Westmead, New South Wales, Australia

${ }^{*}$ Corresponding author:

Akshay Sharma, MBBS

Department of Bone Marrow Transplantation and Cellular Therapy

St. Jude Children's Research Hospital

262 Danny Thomas Place, Mail Stop 1130

Memphis, TN 38105

T: 901-595-2766; F: 901-595-7944

akshay.sharma@stjude.org

Presented in abstract form at the Transplantation \& Cellular Therapy Meetings of ASTCT and CIBMTR, Houston, TX, in February 2019.

\section{Word count:}

Abstract: 200 words

Text: 3257 words

Figures: 5 
Tables: 2

References: 37 


\section{Abstract}

Long-term outcomes after allogeneic hematopoietic cell transplantation (HCT) for therapy-related myeloid neoplasms (tMNs) are dismal. There are few multicenter studies defining prognostic factors in pediatric patients with tMNs. We have accumulated the largest cohort of pediatric patients who have undergone HCT for a tMN to perform a multivariate analysis defining factors predictive of long-term survival. Sixty-eight percent of the 401 patients underwent HCT using a myeloablative conditioning (MAC) regimen, but there were no statistically significant differences in the overall survival (OS), event-free survival (EFS), or cumulative incidence of relapse and non-relapse mortality based on the conditioning intensity. Among the recipients of MAC regimens, $38.4 \%$ of deaths were from treatment-related causes, especially acute graft versus host disease (GVHD) and end organ failure, as compared to only $20.9 \%$ of deaths in the reduced intensity conditioning (RIC) cohort. Exposure to total body irradiation (TBI) during conditioning and experiencing grade III/IV acute GVHD were associated with worse OS. In addition, a diagnosis of therapy related myelodysplastic syndrome and having a structurally complex karyotype at tMN diagnosis were associated with worse EFS.

Reduced-toxicity (but not reduced-intensity) regimens might help to decrease relapse while limiting mortality associated with TBI-based HCT conditioning in pediatric patients with tMNs. 


\section{Introduction}

Risk-adapted, dose-intensified, and multimodal regimens have improved cure rates for pediatric patients with cancer in recent decades. One in 900 adults younger than 45 years is a survivor of pediatric cancer. ${ }^{1}$ The continued improvement in outcomes of pediatric cancer has led to a commensurate increase in survivors, which is expected to increase late sequelae of intensive chemotherapy.

Therapy-related myeloid neoplasms (tMNs) remain a devastating late complication in long-term survivors ${ }^{2}$ and have been reported in children and adolescents treated for hematologic malignancies and solid tumors. ${ }^{3,4}$ Therapy-related acute myeloid leukemia (tAML) accounts for approximately $10 \%-20 \%$ of $A M L$ cases $^{5}$ and develops in approximately $0.8 \%-6.3 \%$ of survivors at a median of approximately $3-5$ years from initial treatment exposure. ${ }^{6}$ Patients with tAML have worse outcomes than do patients with de novo AML, with a median survival of $<1$ year from diagnosis. ${ }^{5,7}$ Allogeneic hematopoietic cell transplantation (HCT) is the only treatment that offers the possibility of long-term cure. ${ }^{8,9}$ However, even with HCT, the overall survival remains a dismal $22 \%-35 \%$. Specifically, the non-relapse mortality (NRM) remains high at $37 \%-48 \%,{ }^{10-12}$ probably as a result of intensive myeloablative conditioning regimens being used.

Most previous studies of outcomes in patients with tMNs and factors affecting survival have predominantly focused on adults; pediatric-specific studies have been limited to small, single-center analyses..$^{2,13-17}$ It is unknown whether outcomes in pediatric patients with tMNs differ based on the antecedent diagnosis or whether the conditioning 
regimen intensity affects the prognosis. Herein we report the results of a multiinstitutional international retrospective collaborative study focusing exclusively on pediatric patients undergoing HCT for tMNs.

\section{Methods}

\section{Study design and participants}

Pediatric transplant centers in the United States, Mexico, Europe, and Australia were invited to participate in this collaborative study. Centers were asked to report patients with therapy-related myelodysplastic syndrome (tMDS) or tAML who were aged 21 years or younger at the time of $\mathrm{HCT}$ and who received transplants at the centers between 1995 and 2017 (both years included). Therapy related myeloid neoplasms were defined according to the 2017 World Health Organization (WHO) criteria. ${ }^{18}$ tAML and tMDS were differentiated based on blast count $>20 \%$ or $<20 \%$ respectively, although the current version of the WHO classification does not differentiate between them based on blast count or degree of dysplasia. ${ }^{18}$ Patients with known inherited genetic predisposition disorders (like Fanconi anemia, or Li-Fraumeni syndrome) were not included in this study. De-identified patient, disease, and transplant-related characteristics were collected using a secured REDCap database after obtaining approvals from the respective institutional review boards.

\section{Definitions}

Therapy-related myeloid neoplasms were defined as those occurring after previous cytotoxic therapy exposure, with tAML being differentiated from tMDS based on a blast 
count of $>20 \%$ in the peripheral blood or bone marrow. ${ }^{19}$ Myeloablative conditioning (MAC) and reduced-intensity conditioning (RIC) regimens were defined by the respective centers. Conditioning regimens were considered as MAC if they included cumulative doses of $>8$ Gy of total body irradiation (TBI) and $>8 \mathrm{mg} / \mathrm{kg}$ of busulfan or $>140 \mathrm{mg} / \mathrm{m}^{2}$ of melphalan administered intravenously. RIC regimens comprised submyeloablative doses of these conditioning agents.

Cytogenetic abnormalities were classified as follows: a structurally complex karyotype was defined as having at least three chromosomal aberrations, involving at least one structural aberration defined as a deletion, duplication, translocation, insertion, inversion, ring chromosome, or isochromosome. The trisomy 8 group could include up to two additional aberrations other than monosomy 7 and structurally complex mutations. Monosomy 7 included the complete or partial loss of chromosome 7 along with additional aneuploidies or deletions, because the clinical outcomes are similar in primary MDS.

Overall survival (OS) was defined as the time from HCT until death from any cause, censoring those patients who remained alive at last follow-up. Event-free survival (EFS) was defined as the time from HCT until first relapse or death from any cause, censoring those patients who had experienced no such event at the last follow-up. Relapse was defined as relapse of tMDS/AML, considering deaths from any cause as competing events. NRM was defined as death without relapse, considering death due to relapse as a competing event. 


\section{Statistical analysis}

Overall survival and EFS curves/functions were estimated by the Kaplan-Meier method and compared by the log-rank test. Single-factor and multiple-factor analysis of OS and EFS were performed by fitting Cox regression models. To assess the relation between the conditioning regimen and transplant outcomes (OS, EFS, relapse, and NRM), conditioning regimen and an independent covariate with a univariate $P$ value of $\leq 0.25$ were included in the multivariate Cox proportional hazards models and Fine-Gray regression models. Race, Lansky/Karnofsky performance status, maximum chronic graft vs. host disease (GVHD) grade, cytomegalovirus serostatus, and degree of HLA match (N/6) were not included because of the large proportion of missing data (for $>35 \%$ patients). The cumulative incidence curve/function was estimated by the Kalbfleisch-Prentice method, accounting for competing risks, and compared by Gray's test. Single-factor and multiple-factor analysis of the cumulative relapse risk was performed by fitting Fine-Gray regression models.

\section{Results}

\section{Patient characteristics}

Fifty-four centers (19 in the USA, 24 in France, seven in the UK, two in Australia, one in Mexico, and one in the Netherlands) contributed data on 401 patients. Demographic details of these patients, initial diagnoses, HCT status, and final outcomes are provided in Table 1. Primary diagnoses included solid tumors (including brain tumors) in 39\% and malignant hematologic neoplasm (ALL, AML, MDS, or lymphoma) in $33 \%$ of the 
patients. Primary diagnosis was not available (not recorded) for $28 \%$ patients. Most patients (65\%) later developed tMDS; only $30 \%$ had tAML. Median age at HCT was 12.9 years (range, 1.2-21 years), and median time from tMN diagnosis to HCT was 3.9 months (range, 0.3-67.2 months). Sixty-eight percent of patients underwent HCT with a MAC regimen, whereas $30.7 \%$ received an RIC regimen before $\mathrm{HCT}$. The MAC and RIC cohorts were comparable except as noted below. RIC recipients were more likely to receive a graft from a mismatched related donor (usually a haploidentical parent) ( $22.8 \%$ vs. $7.7 \%$ ), less likely to receive a cord blood transplant $(14.6 \%$ vs. $20.2 \%$, $P<0.001)$, and more likely to receive a peripheral blood-derived stem-cell graft $(35.8 \%$ vs. $20.5 \%, P=0.006$ ) when compared to MAC recipients. RIC recipients were also more likely to experience grade II-IV acute GVHD (40.7\% vs $27.5 \%, P=0.006)$. Median follow-up for the entire cohort and for the MAC and RIC cohorts separately was 18.3 months, 21.5 months and 16.7 months, respectively.

\section{Overall survival}

There was no significant difference in the survival probability of the two cohorts based on the HCT conditioning intensity $(P=0.171)$. The estimated OS at 1,5 , and 10 years was $65.3 \%, 34.6 \%$ and $32.4 \%$, respectively, for the RIC cohort and $62.8 \%, 49.9 \%$, and 47.8\%, respectively, for the MAC cohort (Fig. 1A). Overall, 235 deaths were reported in the entire cohort, a rate of $58.6 \%$. The fraction of patients in the RIC and MAC cohorts who died as a result of disease relapse, persistence, or progression was similar at $46 \%$. Among the MAC recipients, 151 (55.3\%) died, of whom 58 (38.4\% of the recipients) died of treatment-related causes. Among the RIC recipients, 81 (65.9\%) died, with only 
17 deaths (representing $20.9 \%$ of the recipients) being attributable to treatment-related toxicity (Table 2). In a univariate analysis, performance status $<90$ (hazard ratio [HR] $1.8,95 \% \mathrm{Cl} 1.2-2.8, P=0.006)$, exposure to TBI during conditioning $(\mathrm{HR} 1.9,95 \% \mathrm{Cl}$ 1.4-2.6, $P<0.001)$, experiencing grade III/IV acute GVHD (HR 2.5, 95\% Cl 1.6-4.1 for grade III and $\mathrm{HR} 2.4,95 \% \mathrm{Cl} 1.1-5.2$ for grade IV, $P=0.001$ ), and receiving a transplant from a mismatched donor $(\mathrm{HR} 1.5,95 \% \mathrm{Cl} 1.0-2.1, P=0.029)$ were all associated with a higher HR (Supplementary Table 1). Only TBI exposure (HR 1.8, $95 \% \mathrm{Cl} 1.1-2.8, P=0.018)$ and experiencing grade III/IV acute GVHD (HR 2.2, 95\% Cl 1.2-4.2 for grade III and $\mathrm{HR} 3.0,95 \% \mathrm{Cl} 1.2-7.9$, for grade IV, $P=0.007$ ) remained significantly associated with survival in the multivariable analysis (Fig. 2).

\section{Relapse}

The estimated EFS at 1,5 , and 10 years was $52.5 \%, 29.5 \%$, and $27.6 \%$, respectively, for the RIC cohort and $51.9 \%, 41.2 \%$, and $40.2 \%$, respectively, for the MAC cohort $(P=0.20)($ Fig. 1B). The cumulative incidence of relapse at 1,5 , and 10 years was $33.6 \%, 42.0 \%$, and $42.0 \%$, respectively, for the RIC cohort and $27.5 \%, 34.2 \%$, and $35.2 \%$, respectively, for the MAC cohort $(P=0.176)$ (Fig. 1C). In a univariate analysis for EFS, performance status $<90(\mathrm{HR} 1.6,95 \% \mathrm{Cl} 1.1-2.5, P=0.015)$, having a structurally complex karyotype at $\mathrm{tMN}$ diagnosis $(\mathrm{HR} 1.9,95 \% \mathrm{Cl} 1.0-3.5, P=0.017)$, a tMDS diagnosis (HR 1.4, 95\% $\mathrm{Cl} 1.0-1.9, P=0.039$ ), receiving TBI during conditioning (HR 1.8, 95\% Cl 1.4-2.4, $P<0.001)$ and experiencing grade III/IV acute GVHD (HR 2.1, 95\% Cl 1.3-3.2 for grade III and $\mathrm{HR} 2.0,95 \% \mathrm{Cl} 1.0-3.9$ for grade IV, $P=0.008$ ) were all associated with a higher HR (Supplementary Table 1). Of these, monosomy 7 or a 
complex karyotype at tMN diagnosis (HR 1.6, 95\% Cl 0.7-3.4 for monosomy 7 and HR $2.0,95 \% \mathrm{Cl} 0.9-4.6$, for structurally complex karyotype, $P=0.001$ ) were the only variables associated with a higher HR for relapse in the univariate model

(Supplementary Table 1). In a multivariable model, a tMDS diagnosis (HR 1.6, 95\% Cl 1.0-2.4, $P=0.034$ ), having a structurally complex karyotype at tMN diagnosis (HR 2.3, $95 \% \mathrm{Cl} 1.0-5.0, P=0.006)$, receiving TBI during conditioning (HR 1.7, 95\% Cl 1.1-2.6, $P=0.026)$, and experiencing grade III/IV acute GVHD (HR 2.1, 95\% $\mathrm{Cl} 1.1-4.0$ for grade III and HR 2.5, 95\% Cl 1.0-6.3 for grade IV acute GVHD, $P=0.005)$ remained significantly associated with EFS, whereas a tMDS diagnosis (HR 1.8, 95\% Cl 1.1-2.9, $P=0.028)$ and having a structurally complex karyotype $(\mathrm{HR} 2.7,95 \% \mathrm{Cl} 1.1-6.7$, $P=0.001$ ) were associated with a higher HR for relapse (Figs. 3 and 4).

\section{Non-relapse mortality}

The cumulative incidence of NRM at 1, 5, and 10 years was $14.5 \%, 29.2 \%$, and $31.4 \%$, respectively, for the RIC cohort and $21.0 \%, 24.3 \%$, and $24.3 \%$, respectively, for the MAC cohort $(P=0.63)$ (Fig. 1D). Table 2 lists the primary causes of death. In a univariate analysis for NRM, year of transplant before 2014 (the HR was higher for earlier years, $P=0.012$ ), a primary diagnosis of AML (HR 3.4, 95\% Cl 1.9-5.9, $P<0.001)$, receiving TBI during conditioning (HR 1.8,95\% $\mathrm{Cl} 1.8-2.8, P=0.005)$, and experiencing grade III/IV acute GVHD (HR 3.1, 95\% CI 1.7-5.5 for grade III and HR 4.5, 95\% Cl 1.9-10.6 for grade IV, $P<0.001$ ) were all associated with a higher HR (Supplementary Table 1). Year of transplant before 2014 (the HR was higher for earlier years, $P=0.001)$ and experiencing grade III/IV acute GVHD $(\mathrm{HR} 3.1,95 \% \mathrm{Cl}$ 
1.5-6.1 for grade III and $\mathrm{HR} 4.7,95 \% \mathrm{Cl} 1.9-11.6$ for grade IV, $P=0.001$ ) remained significant predictors of worse NRM in a multivariable model (Fig. 5).

\section{Discussion}

Therapy-related myeloid neoplasms are a challenging late complication of cancer therapy and are associated with dismal outcomes with conventional chemotherapy. ${ }^{5,7}$ Allogeneic HCT is currently the only curative option;8, 10, 11 however, given the rarity of this diagnosis, outcomes data for pediatric patients are limited to small, single-center analyses. ${ }^{2,13-17}$ Furthermore, the factors affecting the prognosis in pediatric patients with tMN are unknown. This retrospective analysis features the largest pediatric cohort of patients with $\mathrm{tMN}$ undergoing $\mathrm{HCT}$ to date, and we have evaluated various prognostic factors associated with disease relapse and survival, particularly focusing on HCT conditioning intensity.

Although we found no significant difference in long-term survival or relapse related to conditioning intensity, some differences were noted. Survival in the first year after HCT appeared to be almost identical in the two cohorts ( $65.3 \%$ for RIC vs $62.8 \%$ for MAC). However, survival fell precipitously in the RIC cohort during years 2-5 after HCT (48.5\% at 2 years and $34.6 \%$ at 5 years after $\mathrm{HCT}$ ). In contrast, although survival declined in the MAC recipients, the fall was more gradual (to $55.1 \%$ at 2 years and $49.9 \%$ at 5 years after HCT). Exposure to TBI and developing grade III/IV acute GVHD were associated with worse OS in the multivariate model. Additionally, non-TBI-based regimens were associated with better EFS. Therefore, less toxic (but not less intense) alkylator-based regimens might be preferred based on superior EFS. 
The cumulative incidence of relapse continued to increase for up to 5 years in both cohorts, and the rate of relapse appeared to be higher in RIC recipients in the 1 to $3-$ years range than in other patients. In a multivariate analysis, the only factors associated with an increased incidence of relapse were a diagnosis of tMDS and the presence of a

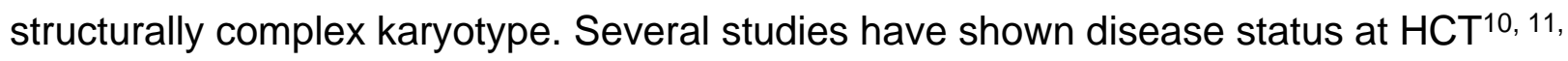
20,21 and high-risk cytogenetic features ${ }^{7,10,12,21}$ to be associated with increased relapse rate and poor survival. A diagnosis of tMDS, as compared to tAML, at HCT was associated with worse EFS; the higher risk of relapse is probably explained by patients with MDS proceeding to HCT without receiving prior disease-directed/debulking therapy. ${ }^{22,23}$ These patients might have had low-level smoldering disease at the time of HCT that resulted in relapse. Although this hypothesis cannot be tested in our cohort, previous reports are certainly suggestive of this explanation ${ }^{22}$ hence, patients with tMDS might benefit from induction chemotherapy before receiving consolidation $\mathrm{HCT}$, even though the quantifiable disease burden is low.

Disappointingly, the cumulative incidence of NRM was comparable in the RIC and the MAC cohorts, even though the causes of death in the patients were quite different. Death from treatment-related causes, especially acute GVHD and end organ failure, was more common in the MAC cohort than in the RIC cohort. These two causes appear to be responsible for the higher incidence of early mortality in our MAC cohort and in many previous studies. ${ }^{7,9,11,14,17}$ Accordingly, multivariate analysis also suggested that grade III/IV acute GVHD and receiving a transplant before 2014 (versus after 2014) 
were both associated with increased NRM. Presumably, better supportive care measures have reduced transplant-related morbidity and mortality in recent years. ${ }^{24}$

Even though the differences in survival are not statistically significant, RIC appeared to offer no survival advantage in heavily pretreated pediatric patients with tMNs. This finding offers some insight into the pattern of mortality and morbidity in patients with tMNs, who are likely to have accumulated significant end organ damage from previous therapy when compared to peers with de novo leukemia. These data suggest that nonTBI-based MAC should be prioritized for pediatric patients with tMNs, if they are suitably healthy, to achieve durable long-term remission. In a randomized trial comparing MAC with RIC in adult patients with de novo AML or MDS, RIC was associated with lower treatment-related mortality but higher relapse rates, resulting in OS being better with MAC. ${ }^{25}$ However, in contrast to the present study, this earlier study did not evaluate outcomes specifically in a highly vulnerable population of pediatric patients with tAML/tMDS. Our findings are consistent with previous reports concerning a cohort of adults with tAML and a prior history of a solid tumor or MDS/MPN. ${ }^{20,21}$ Interestingly, another analysis from the same European registry showed that patients with tAML had superior survival with RIC if they had had a previous diagnosis of a lymphoid malignancy..$^{22}$ In our cohort, antecedent disease diagnosis was associated only with NRM (not with OS, EFS, or relapse) in the univariate analysis; it was not significantly associated with any outcome in the multivariable analysis. 
There is increasing evidence that second malignant neoplasms of the myeloid lineage may occur due to an underlying genetic predisposition and that exposure to chemotherapy may not be the sole driver. ${ }^{26,27}$ Indeed, in one study of adult patients with $\mathrm{tMN}$, around $13 \%$ patients harbored deleterious pathogenic germline variants (most commonly in TP53). ${ }^{26}$ These mutations were even found in the early hematopoietic stem cells (HSC) and these HSCs bearing (pre-)tMN mutations were present years before disease onset or chemotherapy exposure. ${ }^{26,28,29}$ However, in a recent analysis of 84 pediatric patients with tMN, which included many patients also included in this study, investigators found that contrary to adults with $\mathrm{tMN}$, in pediatric patients with tMN there was no evidence of pre-existing minor clones with germline mutations. ${ }^{30}$ KMT2Ar and Ras/MAPK pathway mutations were the most common driver alterations in pediatric patients with tMN, and while TP53 mutations were identified, these were not present in the germline like in the adult tMN patients. ${ }^{30}$ However, recent studies have shown that some pediatric tMN patients may have a genetic mutational signature similar to relapsed mismatch repair-deficient $A L L,{ }^{30,31}$ which could imply a poor tolerance to genotoxic conditioning. Short telomere length, due to inherited genetic syndromes or acquired exposures, may also lead to impaired cellular recovery after myeloablative conditioning and therefore increased toxicity from transplantation. In a study of adult MDS patients undergoing $\mathrm{HCT}$, short pretransplant recipient telomeres were independently associated with inferior survival due to high NRM. ${ }^{32}$ This association was highly significant in patients who developed severe acute GVHD. ${ }^{32}$ In our study as well, developing severe acute GVHD was associated with a worse OS suggesting that perhaps telomere shortening induced by prior chemotherapy exposure pretransplant 
may have limited tissue recovery after myeloablative conditioning in these patients and hence led to increased organ-toxicity and treatment-related mortality, especially in the patients exposed to TBI containing regimens. These observations strengthen the argument that not only are tMNs a diverse group of myeloid malignancies with variable outcomes, but pediatric patients may have had very different antecedent exposures and origins of tMN which must be taken into account when determining the best conditioning regimen. Furthermore, outcomes in studies involving predominantly adult patients might not be applicable to pediatric patients because the treatment intensity and associated comorbidities after prior diagnoses are very different.

This study has several limitations. Given its retrospective nature, some data is incomplete or missing, and information about treatment regimens for antecedent malignant neoplasms was unavailable. Accordingly, we excluded several variables with a large proportion of missing data (for $>35 \%$ patients) from the multivariate analysis. The choice of a particular conditioning regimen is based on multiple factors, and there might have been selection bias with regard to conditioning intensity. It appears, however, that many RIC recipients also received grafts from mismatched unrelated donors (MMRDs) or peripheral blood stem cell (PBSC) grafts. Therefore, it is likely, although this cannot be confirmed, that the choice of conditioning regimen was indeed intentional, perhaps with the aim of leveraging a strong graft-versus-leukemia effect. ${ }^{33}$ There was also substantial heterogeneity in the conditioning regimens across multiple centers, but this facilitated a more pragmatic study evaluating the true impact of conditioning intensity rather than a particular drug combination or regimen. Lastly, we 
acknowledge the importance of comorbid conditions, ${ }^{34}$ disease risk index,${ }^{35}$ and hematopoietic cell transplant comorbidity index $(\mathrm{HCT}-\mathrm{Cl})^{36}$ in determining outcomes after HCT, but we could use only the cytogenetic classification and performance score for studying associations with outcomes because comprehensive co-morbidity data was lacking. Also, the HCT-Cl might not, in fact, be very predictive of outcomes in pediatric patients. ${ }^{37}$ We recognize that some patients included in our cohort might have been included in previous single-center reports. ${ }^{14,16,17}$ However, previous studies lacked the statistical power necessary for the analyses performed in our combined cohort.

\section{Conclusion}

In conclusion, in this multi-center, large cohort of pediatric patients with tMNs undergoing HCT, RIC-based HCT showed no survival advantage over MAC-based HCT for pediatric patients with tMNs. Although outcomes have improved, the prognosis remains suboptimal, with a modest long-term survival rate of around $50 \%$. As treatmentrelated causes remain the predominant reason for post-HCT mortality, novel reducedtoxicity treatment regimens using immunotherapy, augmented cell-based therapeutics, and targeted agents might prove to be the key to improving long-term survival. 


\section{Author Contributions}

AS, SH, CC and BMT designed the study. AS, YL, IA, HBA, PA, AB, NSB, MBB, JB, CB, JEB, AD, J-HD, HE, MF, AG, NJG, WSG, ESG, KH, RH, MPH, JSH, DJ, KAK, EK, SK, AKK, NAK, YPK, CRL, GL-H, PM, KCM, SN, AO-V, TO, MR, SR, KR, HGR, PAR, MES, PJS, JLS, KS, HJS, MdT, ANU and BV acquired the data and verified it. AS, SH, RJB, CC and BMT analyzed the data. AS and BMT wrote the manuscript, and $Y L, I A$, HBA, PA, AB, NSB, MBB, JB, CB, JEB, AD, J-HD, HE, MF, AG, NJG, WSG, ESG, KH, $\mathrm{RH}, \mathrm{MPH}, \mathrm{JSH}, \mathrm{DJ}, \mathrm{KAK}, \mathrm{EK}, \mathrm{SK}, \mathrm{AKK}, \mathrm{NAK}, \mathrm{YPK}, \mathrm{CRL}, \mathrm{GL}-\mathrm{H}, \mathrm{PM}, \mathrm{KCM}, \mathrm{SN}, \mathrm{AO}-\mathrm{V}$, TO, MR, SR, KR, HGR, PAR, MES, PJS, JLS, KS, HJS, MdT, ANU and BV critically reviewed the manuscript. All authors agree with and take full responsibility for the content of this manuscript.

\section{Acknowledgements}

We would like to thank Keith A. Laycock, PhD, ELS for the scientific editing of the manuscript. We thank Dr. Stephen Gottschalk for helpful comments on the manuscript. We would like to thank our colleagues, advanced practice providers, nurses, data managers and other healthcare professional who participated in patient care and data collection. We also would like to thank the parents, who entrusted the care of our children to us. This work was supported by the American Society of Hematology (Scholar Award to AS) and the American Lebanese Syrian Associated Charities (ALSAC).

\section{Conflicts of Interest}


AS's institution receives support for the conduct of industry sponsored trials from Vertex Pharmaceuticals, CRISPR Therapeutics and Novartis. AS has received consulting fee from Spotlight Therapeutics. HBA reports that she is an employee of BeiGene Ltd and began her employment after the contribution of any clinical data. RJB reports that he currently is an employee of Smith \& Nephew, a position that he transitioned to while this project was ongoing. J-HD reports receiving honoraria from blue bird bio, Orchard, Jazz Pharmaceuticals, Novartis, Sanofi Genzyme and Gilead. MPH serves on the advisory board for Mesoblast. HJS reports personal fees from Jazz Pharmaceuticals. HJS has a patent US-2020-0163997-A1 with royalties paid. BMT has received financial support for research and travel from Miltenyi Biotec. Remaining authors do not have any conflicts of interest to disclose. 


\section{References}

1. Davies SM. Subsequent malignant neoplasms in survivors of childhood cancer: Childhood Cancer Survivor Study (CCSS) studies. Pediatric blood \& cancer 2007; 48(7): 727-730. doi: 10.1002/pbc.21113

2. Aguilera DG, Vaklavas C, Tsimberidou AM, Wen S, Medeiros LJ, Corey SJ. Pediatric therapy-related myelodysplastic syndrome/acute myeloid leukemia: the MD Anderson Cancer Center experience. J Pediatr Hematol Oncol 2009; 31(11): 803-811. e-pub ahead of print 2009/10/06; doi:

10.1097/MPH.0b013e3181ba43dc

3. Bhatia S, Krailo MD, Chen Z, Burden L, Askin FB, Dickman PS et al. Therapyrelated myelodysplasia and acute myeloid leukemia after Ewing sarcoma and primitive neuroectodermal tumor of bone: A report from the Children's Oncology Group. Blood 2007; 109(1): 46-51. doi: 10.1182/blood-2006-01-023101

4. Schmiegelow K, Levinsen MF, Attarbaschi A, Baruchel A, Devidas M, Escherich $G$ et al. Second malignant neoplasms after treatment of childhood acute lymphoblastic leukemia. Journal of clinical oncology : official journal of the American Society of Clinical Oncology 2013; 31(19): 2469-2476. doi: 10.1200/JCO.2012.47.0500

5. Kayser S, Dohner K, Krauter J, Kohne CH, Horst HA, Held G et al. The impact of therapy-related acute myeloid leukemia (AML) on outcome in 2853 adult patients with newly diagnosed AML. Blood 2011; 117(7): 2137-2145. e-pub ahead of print 2010/12/04; doi: 10.1182/blood-2010-08-301713

6. Bhatia S. Therapy-related myelodysplasia and acute myeloid leukemia. Semin Oncol 2013; 40(6): 666-675. e-pub ahead of print 2013/12/18; doi: 10.1053/j.seminoncol.2013.09.013

7. Schoch C, Kern W, Schnittger S, Hiddemann W, Haferlach T. Karyotype is an independent prognostic parameter in therapy-related acute myeloid leukemia (t$A M L)$ : an analysis of 93 patients with t-AML in comparison to 1091 patients with de novo AML. Leukemia 2004; 18(1): 120-125. e-pub ahead of print 2003/10/31; doi: $10.1038 /$ sj.leu.2403187

8. Finke J, Schmoor C, Bertz H, Marks R, Wasch R, Zeiser R et al. Long-term follow-up of therapy-related myelodysplasia and AML patients treated with allogeneic hematopoietic cell transplantation. Bone Marrow Transplant 2016; 51(6): 771-777. e-pub ahead of print 2016/01/12; doi: 10.1038/bmt.2015.338

9. Nilsson C, Hulegardh E, Garelius H, Mollgard L, Brune M, Wahlin A et al. Secondary Acute Myeloid Leukemia and the Role of Allogeneic Stem Cell Transplantation in a Population-Based Setting. Biol Blood Marrow Transplant 
2019; 25(9): 1770-1778. e-pub ahead of print 2019/06/10; doi: 10.1016/j.bbmt.2019.05.038

10. Kroger N, Brand R, van Biezen A, Zander A, Dierlamm J, Niederwieser D et al. Risk factors for therapy-related myelodysplastic syndrome and acute myeloid leukemia treated with allogeneic stem cell transplantation. Haematologica 2009; 94(4): 542-549. doi: 10.3324/haematol.2008.000927

11. Litzow MR, Tarima S, Perez WS, Bolwell BJ, Cairo MS, Camitta BM et al. Allogeneic transplantation for therapy-related myelodysplastic syndrome and acute myeloid leukemia. Blood 2010; 115(9): 1850-1857. doi: 10.1182/blood2009-10-249128

12. Kida M, Usuki K, Uchida N, Fukuda T, Katayama $\mathrm{Y}$, Kondo $\mathrm{T}$ et al. Outcome and Risk Factors for Therapy-Related Myeloid Neoplasms Treated with Allogeneic Stem Cell Transplantation in Japan. Biol Blood Marrow Transplant 2020; 26(8): 1543-1551. e-pub ahead of print 2020/04/23; doi: 10.1016/j.bbmt.2020.04.004

13. Brown CA, Youlden DR, Aitken JF, Moore AS. Therapy-related acute myeloid leukemia following treatment for cancer in childhood: A population-based registry study. Pediatr Blood Cancer 2018; 65(12): e27410. e-pub ahead of print 2018/09/06; doi: 10.1002/pbc.27410

14. Gassas A, Sivaprakasam P, Cummins M, Breslin P, Patrick K, Slatter M et al. High transplant-related mortality associated with haematopoietic stem cell transplantation for paediatric therapy-related acute myeloid leukaemia (t-AML). A study on behalf of the United Kingdom Paediatric Blood and Bone Marrow Transplant Group. Bone Marrow Transplant 2018; 53(9): 1165-1169. e-pub ahead of print 2018/03/17; doi: 10.1038/s41409-018-0157-x

15. Imamura T, Taga T, Takagi M, Kawasaki H, Koh K, Taki T et al. Nationwide survey of therapy-related leukemia in childhood in Japan. Int J Hematol 2018; 108(1): 91-97. e-pub ahead of print 2018/03/27; doi: 10.1007/s12185-018-2439-x

16. Kobos R, Steinherz PG, Kernan NA, Prockop SE, Scaradavou A, Small TN et al. Allogeneic hematopoietic stem cell transplantation for pediatric patients with treatment-related myelodysplastic syndrome or acute myelogenous leukemia. Biol Blood Marrow Transplant 2012; 18(3): 473-480. e-pub ahead of print 2011/11/15; doi: 10.1016/j.bbmt.2011.11.009

17. Woodard P, Barfield R, Hale G, Horwitz E, Leung W, Ribeiro R et al. Outcome of hematopoietic stem cell transplantation for pediatric patients with therapy-related acute myeloid leukemia or myelodysplastic syndrome. Pediatr Blood Cancer 2006; 47(7): 931-935. doi: 10.1002/pbc.20596 
18. Swerdlow SH, Campo E, Harris NL, Jaffe ES, Pileri SA, Stein $\mathrm{H}$ et al. WHO classification of tumours of haematopoietic and lymphoid tissues, International Agency for Research on Cancer: Lyon, France, 2017.

19. Godley LA, Larson RA. Therapy-related myeloid leukemia. Semin Oncol 2008; 35(4): 418-429. e-pub ahead of print 2008/08/12; doi:

10.1053/j.seminoncol.2008.04.012

20. Lee CJ, Labopin M, Beelen D, Finke J, Blaise D, Ganser A et al. Comparative outcomes of myeloablative and reduced-intensity conditioning allogeneic hematopoietic cell transplantation for therapy-related acute myeloid leukemia with prior solid tumor: A report from the acute leukemia working party of the European society for blood and bone marrow transplantation. Am J Hematol 2019; 94(4): 431-438. e-pub ahead of print 2019/01/01; doi: 10.1002/ajh.25395

21. Sengsayadeth S, Gatwood KS, Boumendil A, Labopin M, Finke J, Ganser A et al. Conditioning intensity in secondary AML with prior myelodysplastic syndrome/myeloproliferative disorders: an EBMT ALWP study. Blood Adv 2018; 2(16): 2127-2135. e-pub ahead of print 2018/08/26; doi:

10.1182/bloodadvances.2018019976

22. Gatwood KS, Labopin M, Savani BN, Finke J, Socie G, Beelen D et al. Transplant outcomes for patients with therapy-related acute myeloid leukemia with prior lymphoid malignancy: an ALWP of EBMT study. Bone Marrow Transplant 2020; 55(1): 224-232. e-pub ahead of print 2019/09/19; doi: $10.1038 / \mathrm{s} 41409-019-0673-3$

23. Kroger N. Induction, Bridging, or Straight Ahead: The Ongoing Dilemma of Allografting in Advanced Myelodysplastic Syndrome. Biol Blood Marrow Transplant 2019; 25(8): e247-e249. e-pub ahead of print 2019/06/24; doi: 10.1016/j.bbmt.2019.06.016

24. McDonald GB, Sandmaier BM, Mielcarek M, Sorror M, Pergam SA, Cheng GS et al. Survival, Nonrelapse Mortality, and Relapse-Related Mortality After Allogeneic Hematopoietic Cell Transplantation: Comparing 2003-2007 Versus 2013-2017 Cohorts. Ann Intern Med 2020; 172(4): 229-239. e-pub ahead of print 2020/01/21; doi: 10.7326/M19-2936

25. Scott BL, Pasquini MC, Logan BR, Wu J, Devine SM, Porter DL et al. Myeloablative Versus Reduced-Intensity Hematopoietic Cell Transplantation for Acute Myeloid Leukemia and Myelodysplastic Syndromes. J Clin Oncol 2017; 35(11): 1154-1161. e-pub ahead of print 2017/04/06; doi:

10.1200/JCO.2016.70.7091

26. Singhal D, Hahn CN, Feurstein S, Wee LYA, Moma L, Kutyna MM et al. Targeted gene panels identify a high frequency of pathogenic germline variants in patients 
diagnosed with a hematological malignancy and at least one other independent cancer. Leukemia 2021. e-pub ahead of print 2021/04/15; doi: 10.1038/s41375021-01246-w

27. Gibson CJ, Lindsley RC, Tchekmedyian V, Mar BG, Shi J, Jaiswal S et al. Clonal Hematopoiesis Associated With Adverse Outcomes After Autologous Stem-Cell Transplantation for Lymphoma. J Clin Oncol 2017; 35(14): 1598-1605. e-pub ahead of print 2017/01/10; doi: 10.1200/JCO.2016.71.6712

28. Wong TN, Ramsingh G, Young AL, Miller CA, Touma W, Welch JS et al. Role of TP53 mutations in the origin and evolution of therapy-related acute myeloid leukaemia. Nature 2015; 518(7540): 552-555. e-pub ahead of print 2014/12/10; doi: 10.1038/nature13968

29. Berger G, Kroeze LI, Koorenhof-Scheele TN, de Graaf AO, Yoshida K, Ueno H et al. Early detection and evolution of preleukemic clones in therapy-related myeloid neoplasms following autologous SCT. Blood 2018; 131(16): 1846-1857. e-pub ahead of print 2018/01/10; doi: 10.1182/blood-2017-09-805879

30. Schwartz JR, Ma J, Kamens J, Westover T, Walsh MP, Brady SW et al. The acquisition of molecular drivers in pediatric therapy-related myeloid neoplasms. Nat Commun 2021; 12(1): 985. e-pub ahead of print 2021/02/14; doi: $10.1038 / \mathrm{s} 41467-021-21255-8$

31. Waanders E, Gu Z, Dobson SM, Antic Z, Crawford JC, Ma X et al. Mutational landscape and patterns of clonal evolution in relapsed pediatric acute lymphoblastic leukemia. Blood Cancer Discov 2020; 1(1): 96-111. e-pub ahead of print 2020/08/15; doi: 10.1158/0008-5472.BCD-19-0041

32. Myllymaki M, Redd R, Reilly CR, Saber W, Spellman SR, Gibson CJ et al. Short telomere length predicts nonrelapse mortality after stem cell transplantation for myelodysplastic syndrome. Blood 2020; 136(26): 3070-3081. e-pub ahead of print 2020/12/29; doi: 10.1182/blood.2020005397

33. Baron F, Labopin M, Savani BN, Beohou E, Niederwieser D, Eder M et al. Graftversus-host disease and graft-versus-leukaemia effects in secondary acute myeloid leukaemia: a retrospective, multicentre registry analysis from the Acute Leukaemia Working Party of the EBMT. Br J Haematol 2020; 188(3): 428-437. epub ahead of print 2019/10/16; doi: 10.1111/bjh.16185

34. Kongtim P, Parmar S, Milton DR, Perez JMR, Rondon G, Chen J et al. Impact of a novel prognostic model, hematopoietic cell transplant-composite risk (HCT$\mathrm{CR}$ ), on allogeneic transplant outcomes in patients with acute myeloid leukemia and myelodysplastic syndrome. Bone Marrow Transplant 2019; 54(6): 839-848. e-pub ahead of print 2018/09/28; doi: 10.1038/s41409-018-0344-9 
35. Armand P, Kim HT, Logan BR, Wang Z, Alyea EP, Kalaycio ME et al. Validation and refinement of the Disease Risk Index for allogeneic stem cell transplantation. Blood 2014; 123(23): 3664-3671. e-pub ahead of print 2014/04/20; doi: 10.1182/blood-2014-01-552984

36. Sorror ML, Maris MB, Storb R, Baron F, Sandmaier BM, Maloney DG et al. Hematopoietic cell transplantation (HCT)-specific comorbidity index: a new tool for risk assessment before allogeneic HCT. Blood 2005; 106(8): 2912-2919. epub ahead of print 2005/07/05; doi: 10.1182/blood-2005-05-2004

37. Broglie L, Ruiz J, Jin Z, Kahn JM, Bhatia M, George D et al. Limitations of Applying the Hematopoietic Cell Transplantation Comorbidity Index in Pediatric Patients Receiving Allogeneic Hematopoietic Cell Transplantation. Biol Blood Marrow Transplant 2020. e-pub ahead of print 2020/10/12; doi: 10.1016/j.bbmt.2020.10.003 


\section{Figure Legends}

Figure 1. Outcomes following HCT for tMN stratified by conditioning intensity: (A) overall survival, (B) event-free survival, (C) cumulative incidence of relapse and (D) cumulative incidence of non-relapse mortality.

Figure 2. Multivariable analysis of risk factors associated with overall survival after HCT for tMN.

Figure 3. Multivariable analysis of risk factors associated with event-free survival after HCT for tMN.

Figure 4. Multivariable analysis of risk factors associated with relapse after HCT for tMN.

Figure 5. Multivariable analysis of risk factors associated with non-relapse mortality after HCT for tMN. 


\section{Tables}

Table 1: Patient Characteristics ( $\mathrm{N}=401$ )

\begin{tabular}{|c|c|c|c|c|c|}
\hline Characteristic & $\begin{array}{l}\text { Total } \\
\begin{array}{l}N=401 \\
(100 \%)\end{array}\end{array}$ & $\begin{array}{c}\text { MAC } \\
\text { N=273 } \\
(68.1 \%)\end{array}$ & $\begin{array}{c}\text { RIC } \\
N=123 \\
(30.7 \%)\end{array}$ & $\begin{array}{l}\text { Unknown } \\
N=5(1.2 \%)\end{array}$ & $\begin{array}{c}P^{*} \\
\text { MAC } \\
\text { vs. RIC }\end{array}$ \\
\hline Sex & & & & & 0.391 \\
\hline Male & 208 (51.9) & $143(52.4)$ & $63(51.2)$ & $2(40.0)$ & \\
\hline Female & $155(38.6)$ & $114(41.8)$ & $41(33.3)$ & $0(0.0)$ & \\
\hline Unknown & $38(9.5)$ & $16(5.9)$ & $19(15.5)$ & $3(60.0)$ & \\
\hline Race & & & & & 0.665 \\
\hline White & $178(44.4)$ & $125(45.8)$ & $52(42.3)$ & $1(20.0)$ & \\
\hline Black & $23(5.7)$ & $16(5.9)$ & $7(5.7)$ & $0(0.0)$ & \\
\hline Other & $40(10.0)$ & $31(11.4)$ & $9(7.3)$ & $0(0.0)$ & \\
\hline Unknown & $160(39.9)$ & $101(37.0)$ & $55(44.7)$ & $4(80.0)$ & \\
\hline Primary diagnosis & & & & & 0.130 \\
\hline ALL & $81(20.2)$ & $62(22.7)$ & $17(13.8)$ & $2(40.0)$ & \\
\hline AML & $13(3.2)$ & $8(2.9)$ & $5(4.1)$ & $0(0.0)$ & \\
\hline $\begin{array}{l}\text { Other malignant heme } \\
\text { disorder\# }\end{array}$ & $39(9.7)$ & $23(8.4)$ & $16(13.0)$ & $0(0.0)$ & \\
\hline Solid/brain tumor & $156(38.9)$ & $104(38.1)$ & $50(40.7)$ & $2(40.0)$ & \\
\hline Unknown & $112(27.9)$ & $76(27.8)$ & $35(28.5)$ & $1(20.0)$ & \\
\hline Diagnosis at HCT & & & & & 0.104 \\
\hline tMDS & $261(65.1)$ & $175(64.1)$ & $82(66.7)$ & $4(80.0)$ & \\
\hline tAML & $122(30.4)$ & $93(34.1)$ & $29(23.6)$ & $0(0.0)$ & \\
\hline Unknown & $18(4.5)$ & $5(1.8)$ & $12(9.8)$ & $1(20.0)$ & \\
\hline Age at HCT in years & & & & & 0.270 \\
\hline Mean \pm SD & $12.6 \pm 5.0$ & $12.4 \pm 5.0$ & $13.0 \pm 5.0$ & $10.2 \pm 5.0$ & \\
\hline Median (range) & $\begin{array}{l}12.9(1.2- \\
21.0)\end{array}$ & $\begin{array}{l}12.5(1.2- \\
21.0)\end{array}$ & $\begin{array}{c}13.5(2.8- \\
21.0)\end{array}$ & $\begin{array}{l}10.1(4.8- \\
15.7)\end{array}$ & \\
\hline Unknown & $1(0.2)$ & $0(0.0)$ & $0(0.0)$ & $1(20.0)$ & \\
\hline $\begin{array}{l}\text { Time from tMDS/tAML to } \\
\text { HCT in months }\end{array}$ & & & & & 0.097 \\
\hline Mean \pm SD & $6.5 \pm 8.7$ & $5.9 \pm 8.3$ & $7.5 \pm 9.4$ & $18.0 \pm 9.6$ & \\
\hline Median (range) & $\begin{array}{l}3.9(0.3- \\
67.2)\end{array}$ & $\begin{array}{l}3.8(0.3- \\
67.2)\end{array}$ & $\begin{array}{l}4.4(0.9- \\
60.7)\end{array}$ & $\begin{array}{l}22.9(7.0- \\
24.1)\end{array}$ & \\
\hline Unknown & $7(1.7)$ & $3(1.1)$ & $2(1.7)$ & $2(40.0)$ & \\
\hline Performance status & & & & & 0.516 \\
\hline$\geq 90$ & $212(52.9)$ & $153(56.0)$ & $59(48.0)$ & $0(0.0)$ & \\
\hline$<90$ & $47(11.7)$ & $31(11.4)$ & $15(12.2)$ & $1(20.0)$ & \\
\hline Unknown & $142(35.4)$ & 89 (32.6) & $49(39.8)$ & $4(80.0)$ & \\
\hline Donor type & & & & & $<0.001$ \\
\hline MSD & $103(25.7)$ & $77(28.2)$ & $25(20.3)$ & $1(20.0)$ & \\
\hline MUD & $115(28.7)$ & $78(28.6)$ & $35(28.5)$ & $2(40.0)$ & \\
\hline
\end{tabular}




\begin{tabular}{|c|c|c|c|c|c|}
\hline MMRD & $49(12.2)$ & $21(7.7)$ & $28(22.8)$ & $0(0.0)$ & \\
\hline MMUD & $28(7.0)$ & $22(8.1)$ & $6(4.9)$ & $0(0.0)$ & \\
\hline Cord & $73(18.2)$ & $55(20.2)$ & $18(14.6)$ & $0(0.0)$ & \\
\hline Unknown & $33(8.2)$ & $34(12.5)$ & $13(10.6)$ & $2(40.0)$ & \\
\hline Graft source & & & & & 0.006 \\
\hline BM & $223(55.6)$ & $160(58.6)$ & $61(49.6)$ & $2(40.0)$ & \\
\hline PBSC & $101(25.2)$ & $56(20.5)$ & $44(35.8)$ & $1(20.0)$ & \\
\hline Cord & $73(18.2)$ & 55 (20.2) & $18(14.6)$ & $0(0.0)$ & \\
\hline Unknown & $4(1.0)$ & $2(0.7)$ & $0(0.0)$ & $2(40.0)$ & \\
\hline Cytogenetic category & & & & & 0.138 \\
\hline MLL rearrangement & 69 (17.2) & $54(19.8)$ & $15(12.2)$ & $0(0.0)$ & \\
\hline Monosomy 7 & $67(16.7)$ & $44(16.1)$ & $23(18.7)$ & $0(0.0)$ & \\
\hline Normal/trisomy 8 & $26(6.5)$ & $18(6.6)$ & $6(4.9)$ & $2(40.0)$ & \\
\hline Random aberrations & 65 (16.2) & $42(15.4)$ & $23(18.7)$ & $0(0.0)$ & \\
\hline $\begin{array}{l}\text { Structurally complex } \\
\text { karyotype }\end{array}$ & $36(9.0)$ & $20(7.3)$ & $16(13.0)$ & $0(0.0)$ & \\
\hline Unknown & $138(34.4)$ & $95(34.8)$ & $40(32.5)$ & $3(60.0)$ & \\
\hline Death & & & & & 0.043 \\
\hline Yes & $235(58.6)$ & $151(55.3)$ & $81(65.9)$ & $3(60.0)$ & \\
\hline No & $163(40.7)$ & $121(44.3)$ & 41 (33.3) & $1(20.0)$ & \\
\hline Unknown & $3(0.7)$ & $1(0.4)$ & $1(0.8)$ & $1(20.0)$ & \\
\hline Relapse & & & & & 0.441 \\
\hline Yes & $133(32.9)$ & 87 (31.9) & $44(35.8)$ & $1(20.0)$ & \\
\hline No & $265(66.1)$ & $184(67.4)$ & $78(63.4)$ & $3(60.0)$ & \\
\hline Unknown & $4(1.0)$ & $2(0.7)$ & $1(0.8)$ & $1(20.0)$ & \\
\hline Year of transplant & & & & & $<0.001$ \\
\hline $1995-1999$ & $44(11.0)$ & $41(15.0)$ & $3(2.4)$ & $0(0.0)$ & \\
\hline $2000-2004$ & $66(16.5)$ & $44(16.1)$ & $19(15.5)$ & $0(0.0)$ & \\
\hline 2005-2009 & $85(21.2)$ & $52(19.1)$ & $32(26.0)$ & $3(60.0)$ & \\
\hline 2010-2014 & $141(35.2)$ & $92(33.7)$ & $49(39.8)$ & $1(20.0)$ & \\
\hline 2015-2017 & $64(16.0)$ & $44(16.1)$ & $20(16.3)$ & $0(0.0)$ & \\
\hline Unknown & $1(0.2)$ & $0(0.0)$ & $0(0.0)$ & $1(20.0)$ & \\
\hline TBI & & & & & $<0.001$ \\
\hline Yes & $124(30.9)$ & $103(37.7)$ & $21(17.1)$ & $0(0.0)$ & \\
\hline No & $273(68.1)$ & 169 (61.9) & $101(82.1)$ & $3(60.0)$ & \\
\hline Unknown & $4(1.0)$ & $1(0.4)$ & $1(0.8)$ & $2(40.0)$ & \\
\hline Maximum grade of aGVHD & & & & & 0.006 \\
\hline 0 & $157(39.2)$ & $122(44.7)$ & $33(26.8)$ & $2(40.0)$ & \\
\hline 1 & $58(14.5)$ & $44(16.1)$ & $14(11.4)$ & $0(0.0)$ & \\
\hline II & $66(16.5)$ & $43(15.8)$ & $23(18.7)$ & $0(0.0)$ & \\
\hline III & $43(10.7)$ & $24(8.8)$ & $19(15.5)$ & $0(0.0)$ & \\
\hline IV & $16(4.0)$ & $8(2.9)$ & $8(6.5)$ & $0(0.0)$ & \\
\hline Unknown & $61(15.2)$ & $32(11.7)$ & $26(21.1)$ & $3(60.0)$ & \\
\hline Maximum grade of cGVHD & & & & & 0.661 \\
\hline None & $176(43.9)$ & $123(45.1)$ & $50(40.7)$ & $3(60.0)$ & \\
\hline
\end{tabular}




\begin{tabular}{|l|c|c|c|c|c|}
\hline Mild & $26(6.5)$ & $21(7.7)$ & $5(4.1)$ & $0(0.0)$ & \\
\hline Moderate & $13(3.2)$ & $10(3.7)$ & $3(2.4)$ & $0(0.0)$ & \\
\hline Severe & $15(3.7)$ & $12(4.4)$ & $3(2.4)$ & $0(0.0)$ & \\
\hline $\begin{array}{l}\text { Unknown } \\
\text { CMV serostatus }\end{array}$ & $171(42.6)$ & $107(39.2)$ & $62(50.4)$ & $2(40.0)$ & \\
\hline R+/D+ & $69(17.2)$ & $50(18.3)$ & $19(15.5)$ & $0(0.0)$ & \\
\hline R+/D- & $61(15.2)$ & $45(16.5)$ & $16(13.0)$ & $0(0.0)$ & \\
\hline R-/D+ & $27(6.7)$ & $20(7.3)$ & $7(5.7)$ & $0(0.0)$ & \\
\hline R-/D- & $76(18.9)$ & $55(20.2)$ & $21(17.1)$ & $0(0.0)$ & \\
\hline $\begin{array}{l}\text { Unknown } \\
\text { Degree of matching, N/6 }\end{array}$ & $138(41.9)$ & $103(37.7)$ & $60(48.8)$ & $5(100.0)$ & \\
\hline 3-5 & $89(22.2)$ & $57(20.9)$ & $32(26.0)$ & $0(0.0)$ & \\
\hline 6 & $105(26.2)$ & $86(31.5)$ & $19(15.5)$ & $0(0.0)$ & \\
\hline Unknown & $207(51.6)$ & $130(47.6)$ & $72(58.5)$ & $5(100.0)$ & \\
\hline
\end{tabular}

${ }^{*}$ Chi-square test and $t$-test; unknown category was not included.

\#Other malignant heme disorders included Burkitt lymphoma, chronic myeloid leukemia (CML), myelodysplastic syndrome (MDS), and hemophagocytic lymphohistiocytosis $(\mathrm{HLH})$.

Abbreviations: aGVHD: acute graft versus host disease; ALL: acute lymphoblastic leukemia; AML: acute myeloid leukemia; BM: bone marrow-derived graft; cord: cord blood unit; cGVHD: chronic graft-versus-host disease; CMV: cytomegalovirus (R and D indicate recipient and donor serostatus, respectively); HCT: hematopoietic cell transplant; tAML: therapy-related acute myeloid leukemia; tMDS: therapy-related myelodysplastic syndrome; MAC: myeloablative conditioning; MSD: matched sibling donor; MUD: matched unrelated donor; MMRD: mismatched related donor; MMUD: mismatched unrelated donor; PBSC: peripheral blood-derived hematopoietic progenitor cells; RIC: reduced-intensity conditioning; SD: standard deviation; TBI: total body irradiation. 
Table 2: Primary Cause of Death by Conditioning Intensity

\begin{tabular}{|l|l|l|l|l|}
\hline \multirow{2}{*}{ Primary cause of death } & \multicolumn{3}{|l|}{ Conditioning intensity } \\
\cline { 2 - 5 } & $\begin{array}{l}\text { MAC } \\
\text { N (\%) }\end{array}$ & $\begin{array}{l}\text { RIC } \\
\text { N (\%) }\end{array}$ & $\begin{array}{l}\text { Unknown } \\
\text { N (\%) }\end{array}$ & $\begin{array}{l}\text { Total } \\
\text { N (\%) }\end{array}$ \\
\hline Total number of deaths & 151 & 81 & 3 & 235 \\
\hline Treatment related & $58(38.4)$ & $\begin{array}{l}17 \\
(20.9)\end{array}$ & $1(33.3)$ & $68(32.3)$ \\
\hline Acute GVHD & $7(4.6)$ & $1(1.2)$ & $0(0.0)$ & $8(3.4)$ \\
\hline Chronic GVHD & $8(5.3)$ & $4(4.9)$ & $0(0.0)$ & $12(5.1)$ \\
\hline Graft rejection or failure & $6(4.0)$ & $0(0.0)$ & $0(0.0)$ & $6(2.6)$ \\
\hline Infection* & $11(7.3)$ & $5(6.2)$ & $0(0.0)$ & $16(6.8)$ \\
\hline $\begin{array}{l}\text { Organ failure (not due to GVHD or } \\
\text { infection) }\end{array}$ & $20(13.3)$ & $6(7.4)$ & $0(0.0)$ & $26(11.1)$ \\
\hline Pulmonary complications & $6(4.0)$ & $1(1.2)$ & $1(33.3)$ & $8(3.4)$ \\
\hline Malignancy & $3(2.0)$ & $7(8.6)$ & $0(0.0)$ & $10(4.3)$ \\
\hline $\begin{array}{l}\text { Relapse / persistence / progression of } \\
\text { disease }\end{array}$ & $70(46.4)$ & $\begin{array}{l}37 \\
(45.7)\end{array}$ & $1(33.3)$ & $108(46.0)$ \\
\hline Other & $2(1.3)$ & $1(1.2)$ & $0(0.0)$ & $3(1.3)$ \\
\hline Unknown & $18(11.9)$ & $\begin{array}{l}19 \\
(23.5)\end{array}$ & $1(33.3)$ & $38(16.2)$ \\
\hline
\end{tabular}

*Infection (isolation of an organism leading to sepsis/organ failure with no other ascertainable cause of death in the previous 7 days)

\#Malignancy refers to a malignancy unrelated to the therapy-related myeloid neoplasm diagnosis.

Abbreviations: GVHD: graft-versus-host disease; MAC: myeloablative conditioning; RIC: reduced-intensity conditioning. 